\title{
Electrochemical Scanning Tunneling Microscopy ${ }^{\dagger}$
}

\author{
Erkang WANG \\ Laboratory of Electroanalytical Chemistry, Changchun Institute of Applied Chemistry, \\ Chinese Academy of Sciences, Changchun, Jilin 130022, China
}

\begin{abstract}
An ECSTM apparatus with an ideal tip using a homemade SSX-1A STM instrument has been constructed. STM and ECSTM tips were made by electrochemical etching and insulating with paraffin, silicon rubber or epoxy resin under an optical microscope. In situ imaging of highly oriented pyrolytic graphite (HOPG) shows that the leakage current passing through the tip has been effectively eliminated. By this technique we have studied the growth and mechanism of polypyrrole films on HOPG. Using the STM technique we have also studied a metalloporphyrin compound, FAD and tungstosilicic acid modified on HOPG.
\end{abstract}

Keywords Electrochemical scanning tunneling microscope (ECSTM), STM tips, ECSTM tips, polypyrrole film, highly oriented pyrolytic graphite

In order to meet the requirements for the spatial characterization of a surface with very high resolution, scanning tunneling microscopy (STM) can be used with conducting and semiconducting substrates to obtain information about surface topography on the nanometer
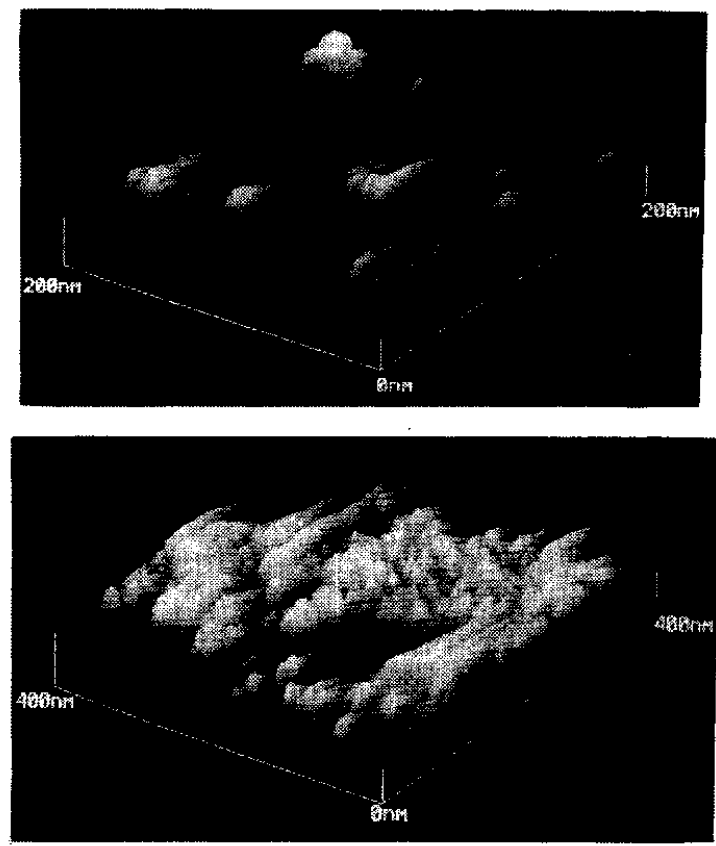

Fig. 1 In situ STM image of polypyrrole micro-islands (a) and large region polypyrrole films (b): $I=1.3 \mathrm{nA} ; E_{\text {tip }}=0.14 \mathrm{~V}$; $E_{\mathrm{HOPG}}=0.60 \mathrm{~V}$; scan frequency, (a) $20 \mathrm{~Hz}$, (b) $18 \mathrm{~Hz}$. Electrodeposition charge: (a) $5.0 \times 10^{-3} \mathrm{C}$; (b) $1.0 \times 10^{-2} \mathrm{C}$.

† Presented at the ASIANALYSIS II, August 9-13, 1993, Changchun, China. scale, and in favorable cases on the atomic (A) level. Thus, a new powerful tool called an in situ electrochemical scanning tunneling microscope (ECSTM) has recently been developed ${ }^{1}$ for studying electrode surfaces and electrochemical processes, such as electrodeposition, corrosion, electroadsorption, electrodeposition, electrocatalysis and electrocrystallization, as well as electropolymerization. The ideal commercial product of in situ ECSTM is yet to be completed. In our research group with Chen, $\mathrm{Li}$, Zhang and Zhang, we have constructed an ECSTM apparatus ${ }^{2}$ with an ideal tip using an SSX-1 A STM instrument made in the Laboratory of Electronic Microscope, Chinese Academy of Sciences, Beijing. For the in situ ECSTM apparatus we took special
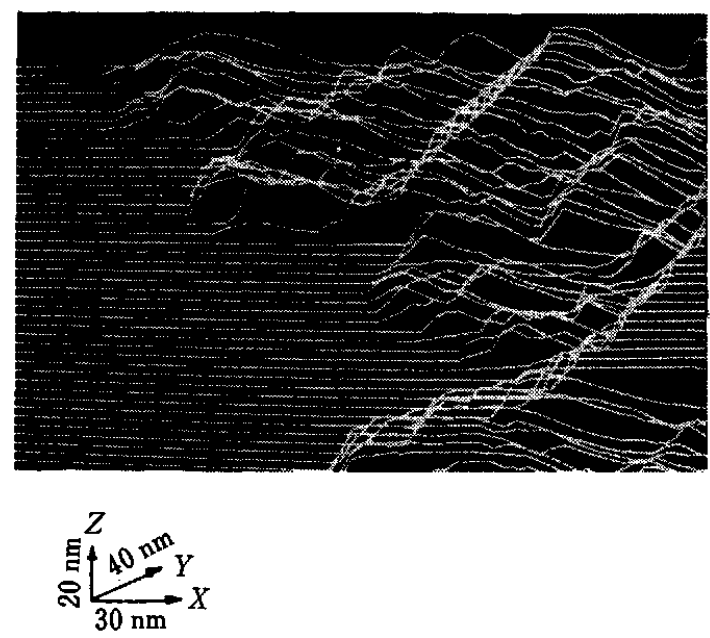

Fig. 2 In situ and real-time images of nickel electrodeposits formed at $-0.825 \mathrm{~V}$ : setting current, $0.84 \mathrm{nA}$; frequency, $12 \mathrm{~Hz}$; electrodeposition charge, $1.6 \mathrm{C} / \mathrm{cm}^{2}$. 


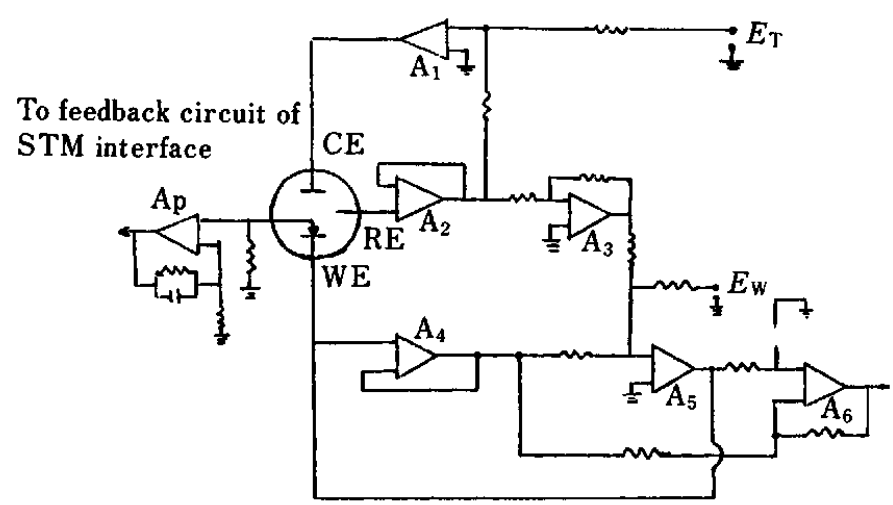

Fig. 3 Schematic illustration of the electronic circuit for a four-electrode configuration, which allowed the potential of the working electrode and the tip with a reference electrode to be controlled simultaneously: counter electrode (CE); reference electrode (RE); working electrode (WE).

measures to decrease the background current passing through the tip. We have successfully fabricated STM and ECSTM tips by electrochemical etching and insulating with paraffin, silicon rubber or epoxy resin under an optical microscope. ${ }^{3-6}$ In situ imaging of highly oriented pyrolytic graphite (HOPG) shows that the leakage current passing though the tip has been eliminated effectively. By STM and ECSTM techniques we have studied the growth and mechanism of polypyrrole films on $\mathrm{HOPG}^{7}$, as shown in Fig. 1. An in situ ECSTM study of the electrodeposition of silver and nickel on HOPG was carried out as shown in Fig. 2.8 By an ex situ STM technique we also studied metalloporphyrin modified HOPG and a glassy carbon (GC) electrode. ${ }^{9,10}$

A schematic diagram of the electronic circuit of the ECSTM and the potential of the electrode are shown in Fig. 3 and Table 1, respectively. The ECSTM tip was prepared by electrochemical etching and then insulated with silicon rubber under an optical microscope. The morphology taken by a scanning electron microscope shows that the silicon rubber coated nearly all parts of the tip, except for $0.5 \mu \mathrm{m}$ at the very end.

By the STM technique we have investigated the surface characteristic of cobalt methyltetraporphyrins (CoTTP) modified on HOPG and a GC (glassy carbon) electrode combined with cyclic voltammograms.9,10 The effect of the electrode surface morphologies on the electrocatalytic activity for dioxygen reduction has been studied and explained on the nanometer scale: that the catalylic activity of the GC electrode is obviously higher than that of HOPG electrode for dioxygen reduction. We have
Table 1 Potential of the electrodes with reference to the coaxial ground and the reference electrode

\begin{tabular}{lcc}
\hline & $\begin{array}{c}v s . \text { Coaxial } \\
\text { ground }\end{array}$ & $\begin{array}{c}v s . \text { Reference } \\
\text { electrode }\end{array}$ \\
Reference electrode & $-E_{\mathrm{r}}$ & 0 \\
Tip & 0 & $E_{\mathrm{r}}$ \\
Working electrode & $E_{\mathrm{W}}-E_{\mathrm{r}}$ & $E_{\mathrm{r}}$ \\
Bias & $E_{\mathrm{w}}-E_{\mathrm{r}}$ & \\
\hline
\end{tabular}

also imaged flavin adenine dinucleotide (FAD) modified on the HOPG surface by adsorption in order to observe a regular geometric pattern in air, of which the dimension suggests that individual molecular image is obtained by STM. ${ }^{11}$ Monomolecular layer tungstosilicic acid $\left(\mathrm{H}_{4} \mathrm{SiW}_{12} \mathrm{O}_{40} \cdot x \mathrm{H}_{2} \mathrm{O}\right)$ deposited on HOPG was observed by STM in air at room temperature. ${ }^{12}$ The molecular dimension of $\mathrm{H}_{4} \mathrm{SiW}_{12} \mathrm{O}_{40}$ measured in the $\mathrm{STM}$ image is consistant with the known crystallographic parameter. We also imaged the monomolecular layer of $\mathrm{H}_{4} \mathrm{SiW}_{12} \mathrm{O}_{40} \cdot x \mathrm{H}_{2} \mathrm{O}$ and the substrate of HOPG, showing that a monomolecular layer of $\mathrm{H}_{4} \mathrm{SiW}_{12} \mathrm{O}_{40} \cdot x \mathrm{H}_{2} \mathrm{O}$ was formed. It has been proved that individual tungstosilicic acid species can be imaged.

The project was supported by National Natural Science Foundation of China.

\section{References}

1. Z. Chen and E. Wang, Anal Chem. (chinese), 20, 969 (1992).

2. Z. Chen, J. Li and E. Wang, J. Electroanal. Chem. Interfacial Electrochem., in press.

3. Z. Chen and E. Wang, et al., Chin. Chem. Lett., 3, 845 (1992).

4. B. Zhang and E. Wang, Electrochim. Acta, in press.

5. Z. Chen and E. Wang, Electroanalysis, in press.

6. B. Zhang and E. Wang, Chin. J. Appl. Chem., 10(1), 1 (1993).

7. J. Li and E. Wang, Chem. J. Chin. Univ., 14, 1227 (1993).

8. Z. Chen, J. Li and E. Wang, J. Electroanal Chem. Interfacial Electrochem., in press.

9. J. Li, B. Zhang and E. Wang, Acta Chim. Sinica, in press.

10. J. Li and E. Wang, Chem. J. Chin. Univ., in press.

11. E. Wang, J. Zhang, Q. Chi and S. Dong, J. Electroanal. Chem. Interfacial Electrochem., in press.

12. B. Zhang and E. Wang, Electrochim. Acta, in press.

(Recieved September 28, 1993)

(Accepted December 25, 1993) 